\title{
Transient Increase in Postnatal Testicular Activity Is Not Revealed by Longitudinal Measurements of Salivary Testosterone
}

\author{
ILPO HUHTANIEMI, LEO DUNKEL, AND JAAKKO PERHEENTUPA
}

Departments of Clinical Chemistry [I.H.], Immunology, and Bacteriology [I.H.], and Children's Hospital [L.D., J.P.J, University of Helsinki, Helsinki, Finland

\begin{abstract}
Testicular steroidogenic activity in 22 boys was monitored longitudinally over the first 6 months of life using salivary $T$ measurements. Samples were collected biweekly. The highest $T$ levels, $130 \pm 12$ pmol/liter (mean $\pm \mathrm{SE}, n=22$ ), were observed on days $2-10$. The values then gradually declined to a mean of about $30 \mathrm{pmol} / \mathrm{liter}$ after month 4 . No secondary peak in salivary $T$ appeared, in contrast to the 1-3-month peak in serum $T$ previously reported. The overall levels of $T$, reflected by the areas under the $T$ concentration curves over the whole period, varied by a factor of three among the subjects studied. It is concluded that postnatal testicular activity may have its most marked physiologic effects immediately after birth rather than at the time of the 1-3-month peak of serum $T$. Furthermore, the overall exposure to androgen is individually greatly variable. (Pediatr Res 20: 1324-1327, 1986)
\end{abstract}

\section{Abbreviations}

BSA, bovine serum albumin

PBS, phosphate-buffered saline

$\mathrm{T}$, testosterone

The pituitary-testicular axis is temporarily activated in boys 1-3 months postpartum. This has been documented by elevated levels of gonadotropins and $\mathrm{T}$ in single serum samples from individual boys (1-6). However, owing to the cross-sectional nature of the previous studies, the timing and duration of testicular activity in individual boys is unknown. Nor is anything known about the physiologic role of the postnatal androgen production. In anticipation of such effects it would be important to know the timing and individual variation of the overall androgen exposure of postnatal boys during the early months of life.

The new sensitive methods for measuring steroids in saliva provide a noninvasive way of monitoring steroid hormone levels. These methods are suitable even for longitudinal observations in healthy neonates. We have therefore made a longitudinal study of salivary $T$ levels in infant boys with the aim of elucidating the course and individual variation of testicular androgen production during the early postnatal months. Since salivary T levels reflect the circulating levels of the biologically active free (non-protein bound) fraction of $T(7,8)$, we actually obtained specific information about the extent of androgen exposure. This can provide

Received March 13, 1986; accepted August 1, 1986.

All correspondence to Dr. Ilpo Huhtaniemi, Department of Physiology, University of Turku, Kiinamyllynkatu 10, SF-20520 Turku, Finland.

This study was supported by grants from the Academy of Finland and the University of Helsinki. us with clues to the physiologic effects of postnatal testicular activity.

\section{MATERIALS AND METHODS}

Subjects. Twenty-two healthy full-term newborn boys were recruited for the study by obtaining informed parental consent. The study was approved by the Ethical Committee of the hospital.

Sample collection and storage. Collection of saliva was taught to the mothers in the hospital during the first 5 days after delivery, when the first sample was collected. Saliva (about $0.5 \mathrm{ml}$ ) was collected before feeding between 0800 and $1000 \mathrm{~h}$ with a plastic Pasteur pipette (Falcon) from below the tongue. If necessary, a small crystal of citric acid was placed on the tongue. The sampling was repeated at home by the parents every other week for 6 months. The samples were stored in home freezers, brought to the hospital during regular check-up visits, and again stored in the laboratory at $-20^{\circ} \mathrm{C}$.

$T$ measurements. The salivary samples were thawed and centrifuged at $800 \times g$ for $10 \mathrm{~min}$. Aliquots of $300 \mu \mathrm{l}$ of the supernatant were extracted twice with $2 \mathrm{ml}$ diethylether. The two extracts were combined, dried under a stream of nitrogen, and resuspended in $300 \mu \mathrm{l}$ of $0.01 \mathrm{M}$ PBS, $\mathrm{pH} 7.4$, containing $0.1 \%$ BSA (PBS-BSA). Recovery of $\left[{ }^{3} \mathrm{H}\right]$-testosterone in this process was over $90 \%$. For radioimmunoassay, a previously characterized antiserum to testosterone-3-carboxymethyloxime-BSA (9) was provided by Dr. D. Apter (Dept. of Medical Chemistry, University of Helsinki). The cross-reactivity of the antiserum was $64 \%$ with $5 \alpha$-dihydrotestosterone, $50 \%$ with $5 \beta$-dihydrotestosterone, $2.7 \%$ with 4 -androstene-3,17-dione, $2.0 \%$ with $5 \alpha$ androstane- $3 \alpha, 17 \beta$-diol, and $<1 \%$ with many other structurally related steroids (9). The antiserum was coupled to Protein-A (Sigma Chemical Co., St. Louis, MO) by incubating a $20-\mu 1$ aliquot with $20 \mathrm{mg}$ protein $A$ in a total volume of $2 \mathrm{ml} 50 \mathrm{mM}$ $\mathrm{NH}_{4} \mathrm{CO}_{3}$ (pH 8.0) overnight at room temperature. The suspension was then washed with PBS, and the pellet was resuspended in the original volume of PBS-BSA and stored at $-20^{\circ} \mathrm{C}$ until used.

A [ $\left.{ }^{125} \mathrm{I}\right]$ iodo-T tracer $(1760 \mathrm{Ci} / \mathrm{mmol}$, from Amersham, UK) was used. Approximately $10,000 \mathrm{cpm}$ of the tracer $(100 \mu \mathrm{l}), 100$ $\mu \mathrm{l}$ of the 1:100 dilution of the antiserum-protein A complex, and a $100-\mu \mathrm{l}$ aliquot of the standards (1-500 fmol/tube) or a salivary extract were incubated overnight at room temperature. The following morning, $2 \mathrm{ml}$ PBS-BSA were added to the tubes, which were then centrifuged at $800 \times g$ for $10 \mathrm{~min}$ and decanted. The pellets were counted in a $\gamma$-spectrometer fitted with an online spline function computer program, provided by the manufacturer (Ria-Gamma, LKB-Wallac, Turku, Finland). The lowest detectable amount was $(n=5) 1.0 \pm 0.3 \mathrm{fmol} /$ assay tube (i.e. 10 $\mathrm{pmol} / \mathrm{liter}$ ), and the intraassay and interassay coefficients of 


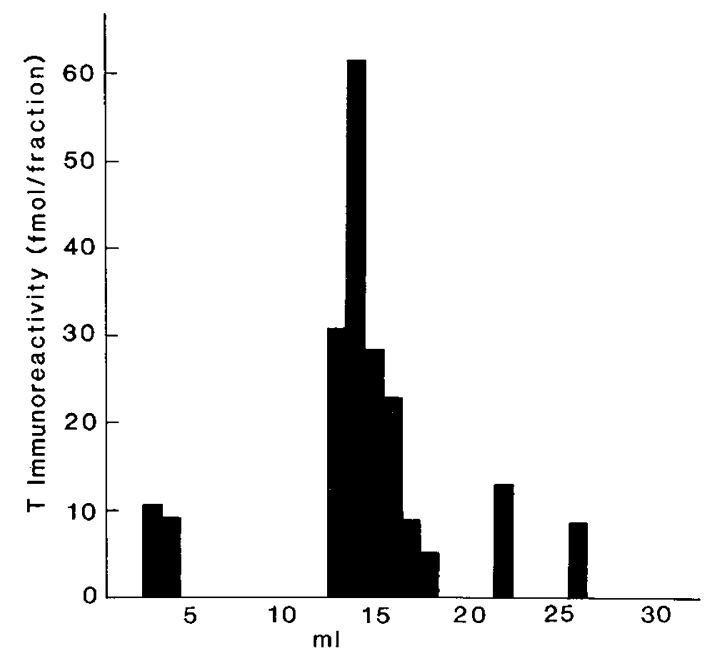

Fig. 1. Elution pattern of $\mathrm{T}$ immunoreactivity from a Lipidex 5000 column. $\left[{ }^{3} \mathrm{H}\right]-\mathrm{T}$ was eluted from the column between 12 and $18 \mathrm{ml}$. Mean data are shown from two salivary pools $(1 \mathrm{ml})$ of five boys under 15 days of age.

variation were $<5$ and $12 \%$, respectively, within the salivary concentration range studied (10-200 pmol/liter). All samples from an individual subject were measured in the same assay run.

In addition to the data on the cross-reactivity of the antiserum (see above), the specificity of the assay was studied by eluting ether extracts of pooled samples of saliva $(1 \mathrm{ml})$ through Lipidex 5000 (Packard-Becker, Groningen, The Netherlands) columns (Fig. 1). The solvent system used was $1.5 \%(0-12 \mathrm{ml}), 10 \%(13-$ $20 \mathrm{ml})$, and $40 \%(21-30 \mathrm{ml})$ chloroform in light petroleum. The eluate was collected in 1-ml fractions, each of which was then dried under nitrogen, reconstituted in $0.5 \mathrm{ml}$ PBS-BSA, and assayed for $\mathrm{T}$ (as above). In two salivary pools collected from boys under 15 days of age, $85 \%$ of the immunoactivity was eluted identically with tritiated $\mathrm{T}$, and the rest in minor peaks with lower and higher polarity (Fig. 1). In pooled saliva from older boys (150-160 days) the $T$ fraction decreased, but the activity in the cross-reacting fractions remained similar (result not shown). Hence, although our nonchromatographic radioimmunoassay method is not strictly specific for $T$, the changes observed in total $\mathrm{T}$ immunoreactivity reliably reflect changes in salivary $\mathrm{T}$ concentration. Furthermore, our method gave mean values $( \pm$ $\mathrm{SE}, n=7$ ) of $256 \pm 37$ and $56 \pm 6.9 \mathrm{pmol} /$ liter for salivary samples collected (between 1200 and $1400 \mathrm{~h}$ ) from young healthy men and women, respectively. These concentrations are in good agreement with those presented by others $(7,8)$.

\section{RESULTS}

The curves of salivary $T$ levels versus age for the individual boys in general showed the highest values in the first samples and then a gradually decreasing course. Surprisingly, no second peak analogous to the month $1-3$ peak of serum $T$ appeared in the salivary $\mathrm{T}$ concentrations (Figs. 2 and 3 ). When all values were grouped for 10-day age periods, the highest mean concentration, $130 \pm 11.5 \mathrm{pmol} /$ liter, occurred at the earliest age (1-10 days, Fig. 2). The values then decreased until day 120 , and thereafter salivary $T$ stayed on a mean level of about $30 \mathrm{pmol} /$ liter to the end of the observation period.

We also calculated the interindividual differences in overall $\mathrm{T}$ activity over the observation period by measuring the area under the $T$ concentration curve over the whole 6-month period for each subject. This was assessed in two ways (Fig. 4), as the total area and as the area above the basal levels of salivary $\mathrm{T}$ (i.e. the mean of the three lowest individual concentrations was consid-

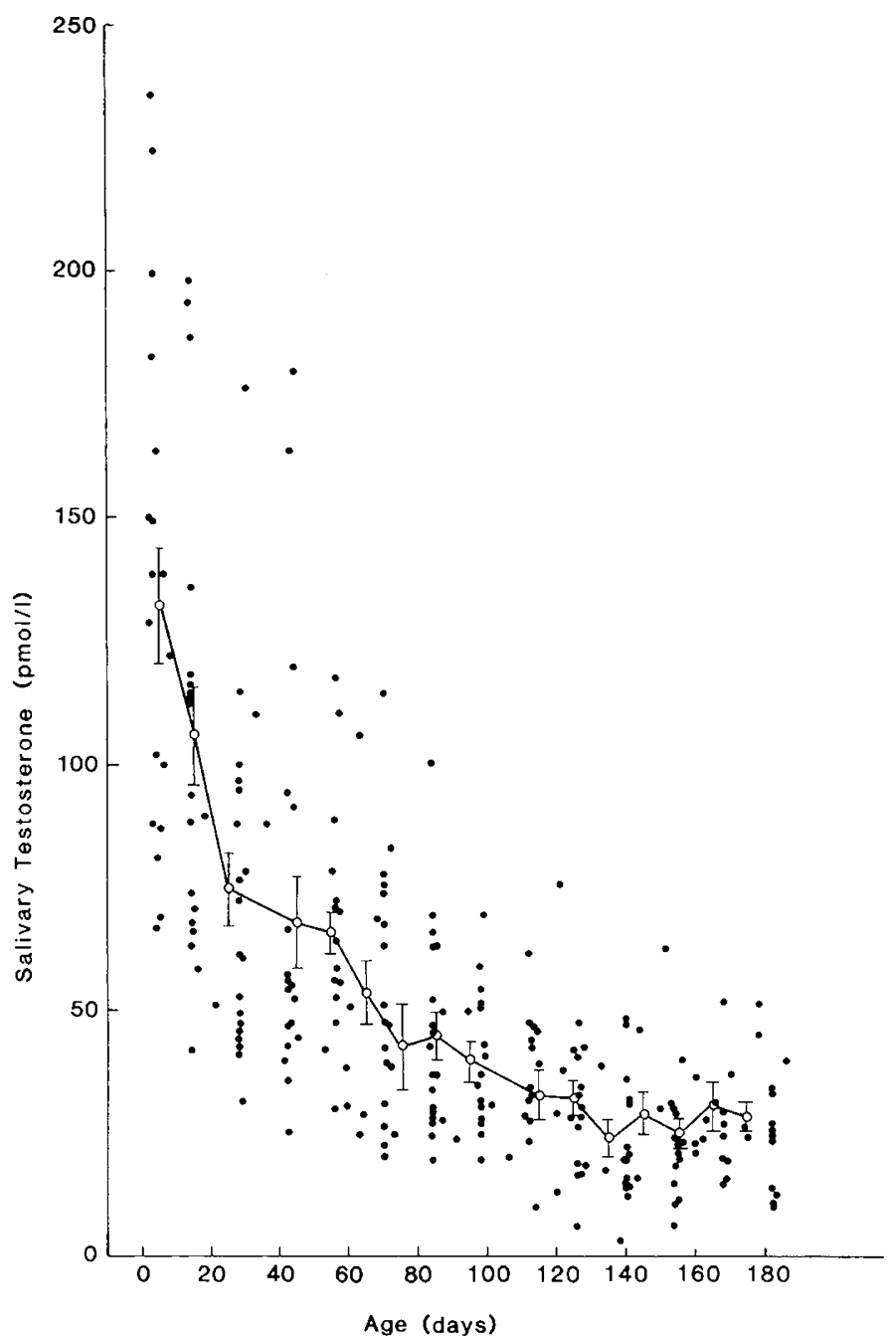

Fig. 2. Distribution of $\mathrm{T}$ levels in the individual salivary samples. Open symbols connected by line, mean $( \pm \mathrm{SE})$ levels for 10-day age periods.

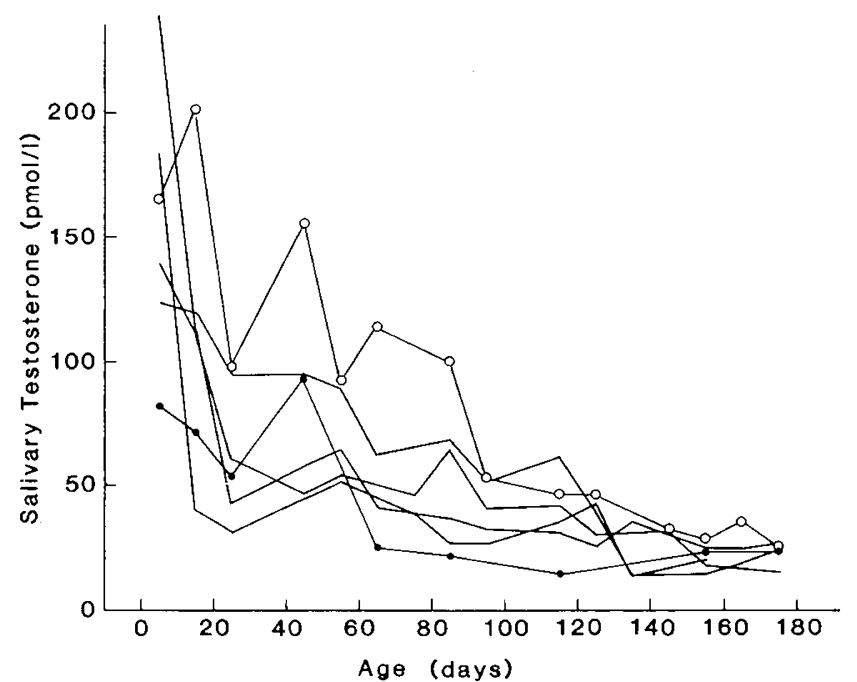

Fig. 3. Longitudinal concentration curves for salivary $\mathrm{T}$ in two individual boys with the largest (open circles) and smallest (closed circles) area under the curve (representing extremes of overall exposure to free $\mathrm{T}$ ). In addition, concentration curves of salivary $\mathrm{T}$ from four other boys, selected at random, are presented (line). 


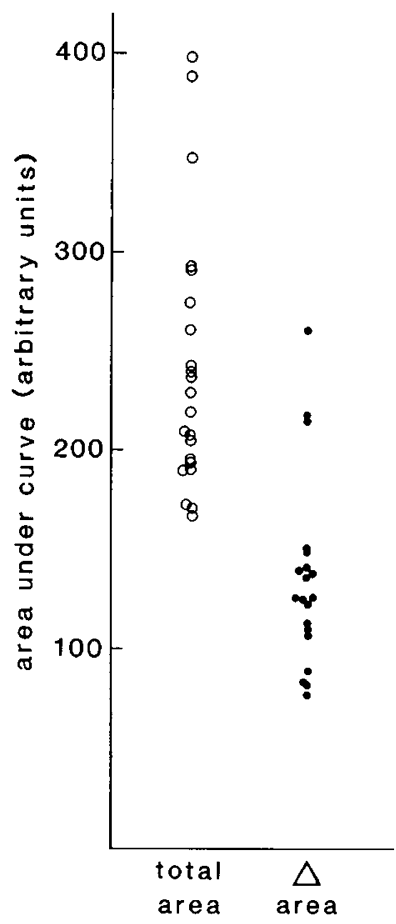

Fig. 4. Distribution of individual areas under the salivary $T$ concentration curves over the first 6 months of life (arbitrary units). Left, total areas; right, areas above the basal T level, defined for each subject as the mean of three lowest values.

ered the plateau). The two methods gave similar distributions with a 2.5-3.5-fold difference between the smallest and largest individual areas. To illustrate the individual differences and trends in $T$ secretion, Figure 3 shows the $T$ concentration curves for the subjects, with the lowest and highest areas under the curve and those of four other boys selected at random.

\section{DISCUSSION}

The salivary steroid concentrations closely reflect the nonprotein bound fractions of serum steroid $(7,8)$, being therefore more direct indicators of biologically active hormone levels. The present measurements of salivary $T$ in young infant boys may thus accurately reflect their exposure to biologically active androgen. Lack of knowledge on the exact correlation between plasma and salivary steroid levels in early infancy indicates caution in the interpretation of the present results. However, the present approach is the only noninvasive method available for longitudinal observations on androgen levels in infants.

Surprisingly, the pattern of postnatal salivary $T$ levels was very different from that previously measured for peripheral serum. The latter levels decrease during the first postnatal week, but a prominent secondary peak appears before 3 months of age (16 ). The low prepubertal levels of serum $T$ are gradually reached toward the age of 12 months $(1-6)$. The salivary $T$ levels, in contrast, were highest at birth and then showed a gradual decline with no sign of a second peak during the early postnatal months. Cho et al. (10) also reported data on salivary $T$ in neonatal boys between 1 and 12 months old. They presented no data on boys younger than 1 month, but in agreement with our findings no increase was found in salivary $T$ between 1 and 2-4 months of age. These observations are at variance with those of Forest et al. (1-3), who, using equilibrium dialysis method, found that free plasma $\mathrm{T}$ levels have a secondary peak parallel with the total plasma $\mathrm{T}$ peak.

The steady decline in salivary $\mathrm{T}$ levels during the first few months after birth occurs simultaneously with the increasing serum concentration of sex-hormone-binding globulin $(11,12)$ and with the increasing degree of binding of $T$ to plasma proteins (1-3). Therefore, the second peak in plasma $T$ may simply be due to increased binding of this steroid to plasma protein in the face of steadily declining levels of nonprotein-bound $T$. Our present findings on salivary $\mathrm{T}$ and the postnatal sex-hormonebinding globulin measurements by others $(11,12)$ agree with this explanation. In addition, they imply that the salivary $\mathrm{T}$ levels reflect free serum $T$ levels also in early infancy, which has not been substantiated by direct measurements.

The testis tissue is clearly under increased gonadotropin support during months 1-3 of age, as demonstrated by measurements of circulating luteinizing hormone and follicle-stimulating hormone $(2,4,6)$. The gonadotropin peak could be a result of decreased negative feedback from the testis, as reflected by the decreased bioactive fraction of circulating T. Experiments in rhesus monkeys show that the testicular negative feedback on gonadotropin secretion is functional in utero (13) and immediately after birth (14). The increased gonadotropin secretion obviously is responsible for the postnatal increase in testicular volume $(10,15,16)$. Whether it also stimulates testicular T production is unclear since Bidlingmaier et al. (16) were recently unable to demonstrate a 2- to 3-month peak in testicular $\mathrm{T}$ concentration. Some increase in $\mathrm{T}$ synthesis is likely due to the gonadotropin peak, but our present findings indicate that it is not reflected by the free fraction of serum T. Practically nothing is known about the physiologic role of the early postnatal testicular activity, although a role may be speculated in testicular descent, morphologic and functional sex differentiation of the central nervous system, and behavior (17-24). Previous measurements of serum gonadotropins and $\mathrm{T}$ have implied coincidence of the maximum androgen effect with the postnatal peak of serum $T$ at the age of 1-3 months. However, our observations suggest that boys are exposed postnatally to the highest free $T$ levels immediately after birth, which therefore may be the crucial period for neonatal androgen action.

Hitherto, postnatal serum $\mathrm{T}$ levels have been measured only from individual serum samples, which can shed no light on longitudinal changes in $T$ production at this age. Salivary $T$ measurements offer such longitudinal information. Our areaunder-curve measurements indicated a roughly 3 -fold difference between extreme values for interindividual overall exposure, which is narrow compared with the normal ranges of many other hormones. Nevertheless, the present data clearly show that individual male infants are quite variably exposed to androgen. Whether this exposure determines any quantifiable parameters in the later life pattern of these individuals is still highly speculative. However, this is the first attempt to quantify the overall androgen exposure and its interindividual variation in early life.

Acknowledgment. The excellent technical assistance of Marjatta Vallas is gratefully acknowledged.

\section{REFERENCES}

1. Forest MG, Sizonenko P, Cathiard AM, Bertrand J 1974 Hypophyso-gonadal function in humans during the first year of life. I. Evidence for testicular activity in early infancy. $J$ Clin Invest 53:819-828

2. Forest MG, de Peretti E, Bertrand J 1976 Hypothalamic-pituitary-gonadal relationships in man from birth to puberty. Clin Endocrinol 5:551-569

3. Forest MG, de Peretti E, Bertrand J 1980 Testicular and andrenal androgens and their binding to plasma proteins in the perinatal period: developmental patterns of plasma testosterone, 4-androstenedione, dehydroepiandrosterone and its sulfate in premature and small for date infants as compared with that of full-term infants. J Steroid Biochem 12:25-36

4. Winter JSD, Faiman C, Hobson WC, Prasad AV, Reyes FI 1975 Pituitarygonadal relations in infancy. I. Patterns of serum gonadotropin concentrations from birth to four years of age in man and chimpanzee. J Clin Endocrinol Metab 40:545-551

5. Winter JSD, Hughes IA, Reyes FI, Faiman C 1976 Pituitary-gonadal relations in infancy. 2. Pattern of serum gonadal steroid concentrations in man from birth to two years of age. J Clin Endocrinol Metab 42:679-686

6. Tapanainen J, Koivisto M, Vihko R, Huhtaniemi I 1981 Enhanced activity of the pituitary-gonadal axis in premature human infants. $\mathbf{J}$ Clin Endocrinol Metab 52:235-238 
7. Riad-Fahmy D, Read GF, Walker RF, Griffiths K 1982 Steroids in saliva for assessing endocrine function. Endocrinol Rev 3:367-395

8. Ferguson DB (ed) 1984 Steroid Hormones in Saliva. Karger AG, Basel, pp 1 162

9. Jänne O, Apter D, Vihko R 1974 Assay of testosterone, progesterone and $17 \alpha$ hydroxyprogesterone in human plasma by radioimmunoassay after separation on hydroxyalkoxypropyl Sephadex. J Steroid Biochem 5:155-162

10. Cho H, Sanayama K, Sasaki N, Nakajima H 1985 Salivary testosterone concentration and testicular volume in male infants. Endocrinol Jpn 32:135140

11. Chaussain JL, Brijawi A, Georges P, Roger M, Donnadieu M, Job JC 1978 Variations of serum testosterone estradiol binding globulin ( $\mathrm{TeBG}$ ) binding capacity in infants during the first year of life. Acta Paediatr Scand 67:649653

12. Bolton NJ, Tapanainen J, Vihko R 1984 Testosterone, sex hormone-binding globulin and the free androgen index in newborns and infants. Abstracts of the 3rd European Workshop on the Testis, Lyon, France, 46

13. Resko JA, Ellinwood WE 1985 Negative feedback regulation of gonadotropin secretion by androgens in fetal rhesus macaques. Biol Reprod 33:346-352

14. Plant TM 1985 A study of the role of the postnatal testis in determining the ontogeny of gonadotropin secretion in the male rhesus monkey (Macaca mulatta). Endocrinology 116:1341-1350

15. Cassorla FG, Golden SM, Johnsonbaugh RE, Heroman WM, Loriaux DL, Sherins RJ 1981 Testicular volume during early infancy. J Pediatr 99:742-
743

16. Bidlingmaier F, Dörr HG, Eisenmenger W, Kuhnle U, Knorr D 1983. Testosterone and androstenedione concentrations in human testis and epididymis during the first two years of life. J Clin Endocrinol Metab 57:311-315

17. Hadziselimovic F 1982 Pathogenesis and treatment of undescended testes. Eur J Pediatr 139:255-265

18. de Lacoste-Utamsing C, Holloway RL 1982 Sexual dimorphism in human corpus callosum. Science 216:1431-1432

19. MacLuskey NJ, Naftolin F 1981 Sexual differentiation of the central nervous system. Science 211:1294-1303

20. Hier DB, Crowley WF 1982 Spatial ability in androgen-deficient men. N Engl J Med 306:1202-1205

21. Gur RC, Gur RE, Obrist WD, Hungerbuhler JP, Younkin D, Rosen AD, Skolnick BE, Reivich M 1982 Sex and handedness differences in cerebral blood flow during rest and cognitive activity. Science 217:659-661

22. Meaney MJ, Stewart J, Poulin P, McEwen BS 1983 Sexual differentiation of social play in rat pups is mediated by the neonatal androgen-receptor system. Neuroendocrinology 37:85-90

23. Money J, Schwartz M, Lewis VG 1984 Adult erotosexual status and female hormonal masculinization and demasculinization: $46, X X$ congenital virilizing adrenal hyperplasia and 46, XY androgen-insensitivity syndrome compared. Psychoneuroendocrinology 9:405-414

24. Swaab DF, Fliers E 1985 A sexually dimorphic nucleus in the human brain Science 228:1113-1115 